\title{
Depression: a review of its definition
}

\begin{abstract}
The current paper has the purpose of reviewing the meaning of depression from a psychological perspective. An analysis of its definition as a symptom, as a syndrome and as a disease is undertaken, along a differentiation of associated concepts such as sadness and melancholy. Some questionings are discussed and a final definition integrating all explicative perspectives is proposed, as a multifactorial disorder in which the individual loses reinforcement from its context and presents difficulties adapting to the everyday life.
\end{abstract}

Keywords: depression, sadness, melancholy, disease
Volume 5 Issue I - 2018

\author{
José Eduardo Rondón Bernard \\ Universidad Central de Venezuela, Instituto de Psicología, \\ Venezuela
}

Correspondence: José Eduardo Rondón Bernard, Universidad Central de Venezuela, Instituto de Psicología, Av Neverí, Mall "Los chaguaramos", office 2-10, Caracas-Venezuela, Tel +58-2 126050339,Email bernard85@gmail.com

Received: December 01, 2017| Published: January 22, 2018

\section{Introduction}

Depression is one of the most popular psychological constructs given the related generated studies and the usage that the general community has made of it. However, confusions about what is really conceived as depression can be seen, often observing interchanges in the conceptions of emotion, state, disorder and disease, and also, being used as a synonym with other alterations such as "melancholy". Derived from the above, the present study intends to make an analysis of the term "depression", starting from its definition and generating later reflections of what is found in the area.

\section{Definition and delimitation}

The word depression comes from the Latin "depressio" which means sinking. The person feels sunk with a weight on their existence. It is a mood disorder that varies from: normal transient low mood in daily life itself, to clinical syndrome, with severe and significant duration and associated signs and symptoms, markedly different from normality.

Depression consists of a disease with decayed mood as its main symptomatology. There are also painful feelings, bad humor, anguish and panic attacks, performance decay of various psychic and cognitive functions, tendency to isolation, demotivation, apathy, abulia, difficulty to enjoy, hopelessness, motor inhibition, hypotonia and negative thoughts, including possible delusions in cases of serious severity. On the other hand, it can present a very diverse associated somatic symptomatology, some organic alterations often corresponding to larval or encapsulated ways of going through a depression. ${ }^{2}$ It is considered a mental disease consisting of a mood disorder, being its usual symptom a state of dejection and unhappiness that may be transient or permanent. ${ }^{3}$ In this sense, it is defined as a mental disorder characterized by the presence of sadness, loss of pleasure, feelings of guilt and low self-esteem, accompanied with alterations in the sleep pattern and the appetite, lack of concentration, and feelings of being tired, which can become chronic and recurrent, making the person dysfunctional in their daily activities; when it is mild it can be treated with psychotherapy, but when it is moderate or severe, pharmacological treatment may be needed. ${ }^{4}$

In the previous cited definitions of recent data, it can be seen how depression is conceived at the same time as a "mental disorder" and as a "mood disorder", although both perspectives coincide in a psychological disorder conception. In addition, it is also emphasized that "it can persist in time, until it makes dysfunctional the one who suffers from it". From these assertions, the following questions arise: how long it does it have to persist? when does it become dysfunctional? the longer, the greater the dysfunction? In this sense the DSM- $5^{5}$ indicates that depressive symptoms must be present for at least two consecutive weeks and that they should cause a significant social deterioration, however, explaining dysfunctionality by means of a "significant social deterioration" could be as well considered subjective, highlighting the need of an operationalization of these symptoms.

Vallejo, ${ }^{6}$ indicates that the term depression is used in three different ways: symptom, syndrome and disease. As a symptom, it can accompany other psychic disorders, such as anguish disorders; as a syndrome, it groups processes characterized by sadness, inhibition, guilt, disability and loss of vital impulse, and as a disease, it is outlined as a disorder of biological origin in which an etiology, a clinic, a course, a prognosis and a specific treatment can be established. From the previous perspective, it seems that depression, if considered a "disease" only to emphasize an organic etiology, could lose both the entity of "disorder" and of "symptom", in contrast to understanding the human being as a biopsychosocial entity and the tripartite biological, psychological and social composition of all alterations that could possibly affect it.

Among other confusions, Jiménez ${ }^{7}$ argues that "depression" is generally interpreted as "melancholy", however, they are different because the latter is more related to longing or memories of the past, more accurately related to sadness of past time(s) "that will not return", while "depression" would be more related to high levels of sadness, discomfort, loss of interest, mental confusion and alterations in the execution of daily activities. Another confusion in history has been the use of the term "depression" as a synonym of "sadness". In this regard, Jiménez ${ }^{7}$ states that sadness is a transient emotional state that varies in intensity and duration, characterized by a pattern of responses that encompasses cognitive-subjective, physiological and motorobservable level changes. The sadness response is usually triggered by unpleasant situations (real or imagined) that are interpreted by the subject as losses, for which the subject generally believes that he or she does not have coping capacity and/or exhausts this capacity, accepting the loss without generating a resource-mobilizing response. In this sense, according to Jiménez, ${ }^{7}$ there is a continuum with the poles "depression" and "non depression", passing by the emotion of "sadness", understanding the latter as a normal reaction of the human being, capable of turning into a pathological state when the intensity, the frequency, and the duration of the emotional answers is excessive. 
As well, Jiménez \& Miguel-Tobal ${ }^{8}$ indicate that the pathological manifestation of the emotion "sadness" actually is what is considered a depression. ${ }^{9}$

In front of this differentiation of "sadness" and "depression", "intensity, frequency and duration" criteria are used to distinguish amongst them, however, limits between each other remain still unclear, and the concept of depression as a "normal emotional reaction" is also introduced. For the purpose of this paper, "sadness" is understood as a basic unpleasant emotion with the function (just like the rest of the emotions) of human adaptation, while "depression" constitutes a maladaptive state mainly characterized by sadness.

\section{Conclusion}

Depression is one the most popular psychological concepts just like stress and resilience, amongst others. This popularity has carried an ambiguous and probably incorrect use of it, with diverse related problems arising. It has been conceived as a thought disorder and as a "mood disorder"; as well, the controversy of its definition as an "emotion" (specifically a sadness synonym) or as a pathological state, can be included. Finally, a conception as a symptom, syndrome or disease has also been part of the discussion. In front of this problem, it is proposed to use "depression disorder" as a reference, along the following definition: Depression constitutes a multi factorial disorder that involves a set of specific behavioral or motor symptoms (agitation or motor slowdown, suicide attempts, general inhibition, crying, poor language, addictions, facial signs of hopelessness and sadness, self-aggression, negative verbalizations, complaints and disarrayed appearance), cognitive symptoms (negative assessment of the self, of the environment and of the future), social symptoms (increase of dependence on others and avoidance of recreational-social interaction) and biological symptoms (weight increase/decrease, insomnia or hypersomnia, fatigue, loss of energy and appetite, altered sexual functioning, diffuse body discomfort, asthenia, muscular and joint pains, and restlessness), that causes the subject to lose reinforcement of their environment consequently generating difficulties in their daily functioning. It should also be stated that "sadness" is an emotion, and as such, it exerts an adaptive function while depression is a state, mainly included in the emotional realm given its characteristic to persist in time and rendering the subject dysfunctional in its environment.

\section{Acknowledgements}

Special thanks to graduate in Psychology Miguel Piñeiro for having successfully contributed in the translation of this article.

\section{Conflict of interest}

There is no economic interest or conflict of interest in the conduct of this study.

\section{References}

1. Rivas-Acuña V, García H, Cruz A, et al. Prevalencia de ansiedad y depresión en las personas con Diabetes Mellitus Tipo 2. Salud en Tabasco. 2011;17(1-2):30-35.

2. Reyes G. Psicoterapia psicodramática: Una forma de diagnóstico y tratamiento para la depresión. Revista Brasileira de Psicodrama. 2013;21(2):53-64

3. Serrano C, Claudia Ivette, Zamora K, et al. Comorbilidad entre depresión y Diabetes Mellitus. Medicina Interna de México. 2012;28(4):325-328.

4. Toro-Tobar R, Grajales-Giraldo F, Sarmiento-López J. Riesgo suicida según la tríada cognitiva negativa, ideación, desesperanza y depresión. Aquichan. 2016;16(4):473-486.

5. Diagnostic and statistical manual of mental disorders. 5th ed. USA: American Psychiatric Association; 2014. 991 p.

6. Vallejo J. Introducción a la psicopatología y psiquiatría. 8th ed. Madrid, Spain: Elsevier Masson; 2015. 712 p

7. Jiménez G. La depresión desde una perspectiva tridimensional: Elaboración de un instrumento de medida. Universidad Complutense de Madrid, Spain; 2002

8. Jiménez G, Miguel-Tobal J. El Cuestionario Tridimensional para la Depresión (CTD): Un nuevo instrumento para medir la tristeza/depresión. Ansiedad y Estrés. 2003;9(1):17-34.

9. Castillo-Quan J, Barrera-Buenfil D, Pérez-Osorio J, et al. Depresión y diabetes: de la epidemiología a la neurobiología. Revista de Neurología. 2010;51(6):347-359. 